\title{
"A SALA DA ALEGRIA": OS SENTIDOS DO ESPAÇO ESCOLAR NA VIDA DOS ALUNOS DA EDUCAÇÃO DE JOVENS E ADULTOS
}

\author{
Lara Luiza Montalvão \\ Rafaela de Carvalho Azevedo \\ Sandra Alves Oliveira \\ Jany Rodrigues Prado
}

1. Universidade do Estado da Bahia (UNEB) Campus XII, Guanambi, BA, Brasil.

2. Universidade do Estado da Bahia (UNEB) Campus XII, Guanambi, BA, Brasil.

3. Universidade do Estado da Bahia (UNEB) Campus XII, Guanambi, BA, Brasil.

4. Universidade do Estado da Bahia (UNEB) Campus XII, Guanambi, BA, Brasil.

Resumo: A Educação de Jovens e Adultos (EJA) é uma modalidade de ensino diferenciada, com sujeitos advindos de realidades difíceis, privados de direitos, envolvendo as questões sociais, econômicas e políticas. Desde os tempos de colonização, as dificuldades educacionais atingem e são reflexos em nossa sociedade atual. Através das políticas públicas essa realidade tem sido modificada, mas ainda se encontra desafios. Os alunos que adentram a EJA já sofreram pela falta da escola, causando circunstâncias maiores, sendo vítimas de opressões e discriminações. É preciso pensar o processo de escolarização atentando as necessidades desses alunos que chegam à escola com objetivos diferentes, porém com o mesmo sonho, aprender a ler. O sentido que eles dão a esse espaço escolar é maior do que o aprendizado técnico, pois envolve o relacionamento uns com os outros, a troca de conhecimento e o bem-estar promovido por esse espaço. Percebe-se a necessidade das conversas, distrações e descontrações no espaço da escola, como forma de interação, facilitando na aprendizagem desse aluno que precisa de um olhar diferenciado, desenvolvendo a humanidade e o respeito. É na alegria expressada pelo olhar e sorrisos que se compreende a tamanha felicidade em aprender e a beleza contida na troca de conhecimentos.

Palavras-chave: Educação de Jovens e Adultos. Sentidos. Escola. Interação.

\begin{abstract}
Youth and Adult Education (EJA) is a differentiated teaching modality, with subjects coming from difficult realities, deprived of rights, involving social, economic and political issues. Since colonial times, educational difficulties have affected and are reflected in our current society. Through public policies, this reality has been modified, but challenges remain. Students entering the EJA have already suffered from the lack of school, causing greater circumstances, being victims of oppression and discrimination. It is necessary to think about the schooling process taking into account the needs of these students who come to school with different goals, but with the same dream, to learn to read. The sense they give to this school space is greater than technical learning, as it involves the relationship with each other, the exchange of knowledge and the well-being promoted by this space. It is perceived the need for conversations, distractions and relaxation in the school space, as a form of interaction, facilitating the learning of this student who needs a different look, developing humanity and respect. It is in the joy expressed by the look and smiles that one understands the happiness in learning and the beauty contained in the exchange of knowledge.
\end{abstract}

\footnotetext{
Apoio financeiro: Nenhum.

Conflitos de interesses: Os autores declaram não haver nenhum conflito de interesse.

Correspondência: rafaela.pedguneb@gmail.com

Recebido: 27 Mai 2020.

Aprovado: 31 Mai 2020

Editor: Marcelo Máximo Purificação.
}

Este é um artigo publicado em acesso aberto (Open Access) sob a licença Creative Commons Attribution, que permite uso, distribuição e reprodução em qualquer meio, sem restrições desde que o trabalho original seja corretamente citado. 
Key-words: Youth and Adult Education. Senses. School. Interaction.

Como citar: MONTALVÃO, L. L; AZEVEDO, R. C; OLIVEIRA, S. A; PRADO, J. R. A sala da alegria: os sentidos do espaço escolar na vida dos alunos da educação de jovens e adultos. Revista Científica Novas Configurações - Diálogos Plurais, Luziânia, v. 1, n.1, p. 80-84, 2020. https://doi.org/.10.4322/2675-4177.2020.011

\section{INTRODUÇÃO}

O componente curricular "Pesquisa e Estágio PE III" ofertado no curso de Pedagogia da Universidade do Estado da Bahia (UNEB), campus XII, possibilita o estudante escolher a turma em que deseja realizar o estágio. Diante disso, foi escolhido como ambiente de formação a Educação de Jovens e Adultos (EJA), com o intuito de vivenciar outro mundo da educação, com novos sujeitos e novas aprendizagens.

Este trabalho apresenta as principais experiências do estágio realizado em uma escola do município de Guanambi-BA que oferta a modalidade de ensino EJA, em uma sala que foi formada especialmente para alfabetizar, ou seja, uma turma completamente diferente das demais e que proporcionou o desafio desejado, contribuindo assim para uma formação profissional e pessoal.

Ao longo da história, o desafio de combate ao analfabetismo tem sido algo discutido e enfatizado no Brasil. A EJA proporciona oportunidades para aqueles que, por vários motivos, não foram alfabetizados na idade certa, não vivenciando o espaço escolar como deveria por direito. Por meio disto, podemos observar como os alunos da EJA são guerreiros que enfrentam dias difíceis de trabalho e mesmo assim estão sempre contentes e cheios de vontade de aprender. Por meio dessa observação e também de alguns relatos, obtidos por entrevistas, que se pode compreender qual o sentindo e o significado que esses sujeitos atribuem a então chamada: "Sala da Alegria".

A entrevista foi um instrumento de pesquisa exigida pelo componente "Estatística e Educação". Ela foi elaborada por meio de uma conversa livre onde surgiram várias discussões, entretanto, com um roteiro predefinido, caracterizando-se em uma entrevista não estruturada (BARROS; LEHFELD, 2007). Por questões éticas, os entrevistados serão identificados por meio das iniciais de seus nomes e a escola também levará nome fictício, sendo ele: "esperança".

\section{A EDUCAÇÃO DE JOVENS E ADULTOS NA “A SALA DA ALEGRIA”}

Segundo a Lei de Diretrizes e Bases da Educação Nacional (LDB), em seu artigo 37, a Educação de Jovens e Adultos é uma modalidade de ensino para os sujeitos que não tiveram acessos ou continuidades do estudo na idade própria (BRASIL, 1996). Percebe-se então que os sujeitos que compõe a EJA são aqueles que por algum motivo não adentraram a escola ou não tiveram condições de permanecer nela.

Desde a época da colonização, o Brasil enfrenta problemas educacionais quanto ao acesso a todos. A influência de Portugal sempre foi forte e evidente desde 1500, as questões econômicas e politicas sempre afetaram essa nova Colônia constituída. Nesse contexto, o Brasil sofreu efeitos, sendo um deles a falta de escolarização da população brasileira. Por isso, são visíveis os efeitos na sociedade atual, porém não se pode atribuir apenas a esse fator, sabendo das diferentes realidades dos sujeitos.

De acordo com os alunos entrevistados, há uma variedade de motivos que os impediram de estar cursando a escola na idade regular, dentre elas estão: Trabalhar para ajudar a família, condição financeira baixa para manter os estudos, proibição de familiares e por fim, falta de interesse. Percebe-se que cada um obteve sua experiência com a educação construindo o seu sentido e significado para a escola. As autoras Costa e Ferreira (2011, p. 12) compreendem sentindo como:

$\{\ldots\}$ aquela concordância sobre algo desde a ocorrência de um diálogo. Estando a conversar, as pessoas discutem um assunto e determinam um sentido para aquilo que falam. O sentido é, portanto, aquele instante, não tem a estabilidade de um significado, pois mudará sempre que mudarem os interlocutores, os eventos. Tem caráter provisório e é revisitado e torna-se novo sentido em situações novas. 
Sendo assim, o sentindo que as pessoas atribuem a certo objeto ou objetivo depende do momento ou situação vivenciada, por exemplo, os alunos que apontaram como motivo de não estar na escola na idade regular a falta de interesse, não atribuiu a escola o mesmo sentido que atribui a escola hoje. Para eles, o ambiente escolar atual despertam vários interesses que vão além do processo de ensino e aprendizagem. Assim como afirmam alguns alunos:

\begin{abstract}
A escola me ajuda em tudo, me dá educação, tudo que pensar que é bom as professoras dá. Sem a escola é ruim, a gente nunca fica sabendo o que está passando, tudo que acontece a gente não vê. (Aluna I, entrevista, out. 2018).
\end{abstract}

É bom estudar que aprende, conhece mais gente e faz mais amizades." (Aluna G, entrevista, out. 2018); Eu falo para as pessoas vim para escola aprender e se não aprender nada pelo menos se diverte e faz uma fisioterapia na memória. Alguma coisa você aprende. (Aluna L, entrevista, out.2018).

As falas demostram que a escola para eles é um lugar de aprendizagens mútuas, troca de saberes, ambiente de socialização e amizades. É nessa mesma perspectiva que os autores do livro Psicologias: Bock, Furtado e Teixeira (2001) apresentam e explicam a teoria interacionista de Levi Vygotsky. Apontando que o indivíduo aprende através da interação com o outro, sendo assim, os professores e colegas formam um conjunto de mediadores do processo de ensino-aprendizagem que ocorre a apropriação da cultura e o desenvolvimento humano.

Essa interação desenvolve uma aprendizagem de vida, na qual, muitos viram na escola como a solução para a solidão e realização pessoal. Construindo através dela relações de parceria que ajudam a vencer suas dificuldades. Por exemplo, Dona I assegura que a escola lhe salvou de uma depressão:

Eu estava entrando em depressão por causa que meu irmão tinha falecido e deixado 4 filhos menor e Cuma é que minha cunhada ia criar esse tanto de filho e logo depois minha cunhada morreu aí agora ficou pior ainda. Ai eu falei o meu Deus me dá um lugar para eu firmar a minha mente, foi aí que minha afilhada me chamou para ir para escola. (Aluna I, entrevista, out.2018)

Além disso, Dona I diz que a relação com seus colegas e professora a ajudou a vencer o vício, pelo cigarro: Eu fumava e N (professora) me ajudou largar o cigarro. Me deu um papel de um lugar que me ajudou e já tem um ano que não coloco um cigarro na boca. Deus no céu e as professoras aqui na terra. (Aluna I, entrevista, out.2018).

Percebe-se então, um novo sentido de escola que encaixa com os versos da poesia "Escola" de Paulo Freire: "A escola é sobre tudo, gente. (...) A escola será cada vez melhor, na medida em que cada ser se comportar como colega, como amigo, como irmão". A poesia relata que a instituição não é só estrutura física e conceito, ela é gente, pois é formada de seres humanos que sentem, lutam e constroem relacionamentos para vencer os obstáculos que a vida apresenta.

Além de apresentar um novo sentindo para escola, também temos um novo sentindo de relação professor e aluno, que se baseiam em um comportamento de colega, amigo e irmão. Afirma-se isso a partir da fala de Dona I e também na fala de Dona A: Agradeço a Deus pelas professoras por me ensinar a Ler. Eu Agradeço todos os dias, (ergue as mãos paro o alto) obrigado Senhor. Abençoa e protege as professoras. Viva Deus no céu e as professoras na terra.” (Aluna A, entrevista, out. 2018).

Na sociedade atual a violência, discriminação, desrespeito, enfim a desumanização tem sido uma realidade que oprime e intensifica a necessidade que se tem de romper com os preconceitos. Os sujeitos da EJA não vêm de uma realidade diferente, pelo contrario, são pessoas sofridas e violentadas pela falta de direitos. Por isso, a escola tem o desafio de acolher os diferentes alunos e compreender as questões cognitivas e sociais que os formam.

É inconcludente pensar numa escola onde não haja preocupação em diferenciar o sujeito, na sua singularidade, onde o processo de inclusão não seja percebido de forma consciente e extensivo a todo segmento da escola, principalmente no processo ensino aprendizagem de todas as modalidades e em particular, na educação de jovens e adultos, devido à relevância dessa modalidade de ensino na construção do conhecimento de pessoas que tardiamente ingressaram na escola, de forma que venha viabilizar e promover condições de desenvolvimento, considerando, as implicações de natureza social e cognitiva. (CALADO, 2008, p. 3).

E por serem sujeitos sofridos que já passaram pela experiência de viver sem a escolarização, é que eles valorizam a escola e os estudos como uma esperança de melhora nas suas questões sócias e cognitivas. Como asseguram alguns alunos: Tem pessoa maldosa que joga na cara da gente, fala para a gente que a gente é burro e não sabe de nada, aí a gente fica sem graça e desfaz da gente por que não sabe ler (Aluna A entrevista, out. 2018); É melhor pegar no lápis, se não depois tem que pegar no cabo da inchada" (Aluna M, entrevista, ou. 2018). 
Os alunos destacam em suas falas a importância de estudar e como à ausência dessa atitude pode causar dor e sofrimento. Além disso, é notável que apesar da maioria obtivessem as mesmas dificuldades de vida, mas cada aluno daquela sala tem a sua singularidade na aprendizagem, ou seja, é uma sala totalmente heterogênea, da qual, pertencem alunos que já sabem ler algumas coisas e alunos que estão começando a juntar a letras agora.

Alguns já sentem o reflexo da escola em sua vida pessoal: Graças à escola eu entro em um mercado e sei a validade do que eu vou comprar e sei se meu dinheiro vai dar para comprar tudo que eu quero (Aluna A, entrevista, out.2018); Para viajar tem o nome do ônibus lá aí eu leio e já sei em qual eu vou pegar (Aluna L, entrevista, out.2018). Gasparin (2007, p. 8) esclarece: “Ao colocar em prática os conhecimentos adquiridos, o sujeito modifica sua realidade imediata. Logo, o conhecimento teórico perde seu caráter de ser apenas "uma compreensão do que acontece", para se tornar "um guia para a ação"”.

O ensino precisa ser mais do que teorias e conceitos, aprende-se a humanização convivendo, envolvendo nas histórias de vida, cooperando, dialogando, tendo consciência do seu papel histórico na realização do ensino e da aprendizagem. Pois é na troca que se encontra a essência do aprender. Gasparin (2007, p.109) afirma:

$\mathrm{Na}$ interação entre professor e aluno dá-se o confronto entre os conceitos ou conhecimentos espontâneos e os conhecimentos científicos. Os conceitos científicos descem à realidade empírica, enquanto os espontâneos ascendem buscando sistematização, abstração, generalização. Por isso, a aquisição dos conceitos científicos implica a reconstrução dos conceitos espontâneos numa articulação e transformação recíprocas.

Dessa forma, a aprendizagem desses sujeitos se dá a partir da interação com aquilo que eles já sabem, sua relação e leitura do mundo onde vivem.

Na Educação de Jovens e Adultos, é preciso romper com os paradigmas, aperfeiçoando cada vez mais um saber humanístico e dotado de conteúdo prático, levando em consideração a experiência de vida dos educandos, como enfatizava Freire (1999, p.25-26) "Quem ensina aprende ao ensinar e quem aprende ensina ao aprender. [...]” Sem dúvidas a troca precisa acontecer para que haja liberdade. Quando eu leio uma palavra é a alegria da minha vida, é uma riqueza. Eu peço Jesus que me ensina para mim saber entrar e sair dos lugares. (Aluna I, entrevista, out.2018).

\section{CONSIDERAÇÕES FINAIS}

Este estudo teve como objetivo compreender os sentidos que os Jovens e Adultos alunos da EJA dão para o espaço escolar. A partir dos estudos e análise é possível afirmar a variedade de sentidos dados pelos sujeitos ao longo de suas vidas, pois existem fatores influentes sejam econômicos, pessoais ou cognitivos. Foi preciso saber as histórias de relações com a escola e o processo de escolarização ao decorrer do tempo vivido, para fazer reflexões sobre o sentido escolar hoje.

Nessa perspectiva, compreende-se que os Jovens e Adultos veem a escola, na modalidade EJA, como uma oportunidade única e necessária para a vida. Eles valorizam o espaço pela relação com os colegas, a distração da mente, como forma de socialização e também aprendizado, tendo como objetivo a leitura e escrita. Diferente da relação que tiveram no período da infância ou em outro momento da vida, onde alguns não puderam ir à escola, ou não quiseram permanecer.

A escola precisa proporcionar esse espaço de troca e bom convívio, sendo esse um fator determinante para que os sujeitos permaneçam na escola e facilite o processo de aprendizagem. Um espaço que possibilite a interação e a troca de experiências de vida, que pode ser proporcionado pela direção escolar, pelos professores e toda a comunidade que compõe a escola. De forma atender as necessidades dos alunos.

Adentrando a essa escola, logo se escuta a frase: Aqui é a sala da Alegria (M), mas só depois da convivência com os sujeitos a cada dia, se compreende que a alegria estar nas pequenas vitórias. Sendo o estudar e a convivência com colegas e professoras que proporcionam através da troca de boas energias, experiências e aprendizagens. Para muitos pode ser um nada, porém, para eles é tudo, é nessa perspectiva de ensino que se pode referir a fala de Paulo Freire $(2004$, p.142) quando diz: " A alegria não chega apenas no encontro do achado, mas faz parte do processo da busca. E ensinar e aprender não pode dar-se fora da procura, fora da boniteza e da alegria". 


\section{REFERÊNCIAS}

BRASIL. Ministério da Educação. Lei de Diretrizes e Bases da Educação Nacional - Lei nº 9.394 de 20 de dezembro de 1996. Brasília-DF,1996.

BARROS, Aidil Jesus da Silveira; LEHFELD, Neide Aparecida de Souza. A pesquisa científica: a coleta de dados. In:__.Fundamentos de Metodologia científica. 3. ed. São Paulo: Pearson Prentice Hall, 2007, p. 105-117.

BOCK, A.M. B; FURTADO. O; TEIXEIRA, M. L.T. Psicologias: uma introdução ao estudo de psicologia. 13 Ed. São Paulo: Saraiva, 2001.

COSTAS, F.A.T; FERREIRA, L.S. Sentido, Significado e Mediação em Vygotsky: implicações para a constituição do processo de leitura. Revista Iberoamericana de Educación. No 55 (2011), pp. 205-223.

CALADO, M. J. A Inclusão de Alunos com Necessidades Educacionais Especiais na Educação de Jovens e Adultos. 2008. Disponível em: http://www.pe.senac.br/ascom/faculdade/edital/II Encontro/cd/A_INCLUSAO_DE_ALUNOS_COM.pdf. Acesso em: 01 de Dez. 2018.

GASPARIN, J. L. Uma didática para a pedagogia histórico-crítica. Campinas: Autores Associados, 2007.

FREIRE, P.; SHOR, I. Medo e ousadia: o cotidiano do professor. Rio de Janeiro: Paz e Terra, 1996.

FREIRE, P. Pedagogia da indignação. São Paulo: UNESP, 2000

FREIRE, P. Pedagogia da autonomia: Saberes necessário à prática educativa. 30 ed. São Paulo: Paz e Terra, 2004 (coleção leitura).

\section{Informações sobre os autores:}

LLM. Graduada em Pedagogia pela Universidade do Estado da Bahia, UNEB - campus XII. E-mail: montalvaolara@gmail.com. Endereço para correspondência: Rua Porto Seguro, nº 261, Centro, IuiúBA.

RCA. Graduada em Pedagogia pela Universidade do Estado da Bahia, UNEB - campus XII. E-mail: rafaela.pedguneb@gmail.com.

SAO. Professora do Departamento de Educação de Guanambi-Campus XII da Universidade do Estado da Bahia (UNEB). Graduação em Pedagogia pela Universidade do Estado da Bahia, Campus XII/Departamento de Educação de Guanambi-BA, especialização em Matemática e Estatística pela Universidade Federal de Lavras e Mestrado em Educação pela Universidade Federal de São Carlos. Doutoranda do Programa de Pós-Graduação em Educação da Universidade Federal de Juiz de Fora (2019). E-mail: soliveira4@ hotmail.com.

JRP. Professora substituta do Departamento de Educação de Guanambi-Campus XII da Universidade do Estado da Bahia (UNEB). graduação em Pedagogia pela Universidade do Estado da Bahia (1999), é Especialista em Metodologia do Ensino Fundamental pela UNEB (2001), em Gestão Educacional UNILATUS (2011) e em Coordenação Pedagógica - UFBA (2016), e Mestra em Educação pela UESB. E-mail: jprado@uneb.br.

Contribuição dos autores: LLM; RCA; SÃO; JRP: conceptualização, captação de recursos, supervisão, redação. 